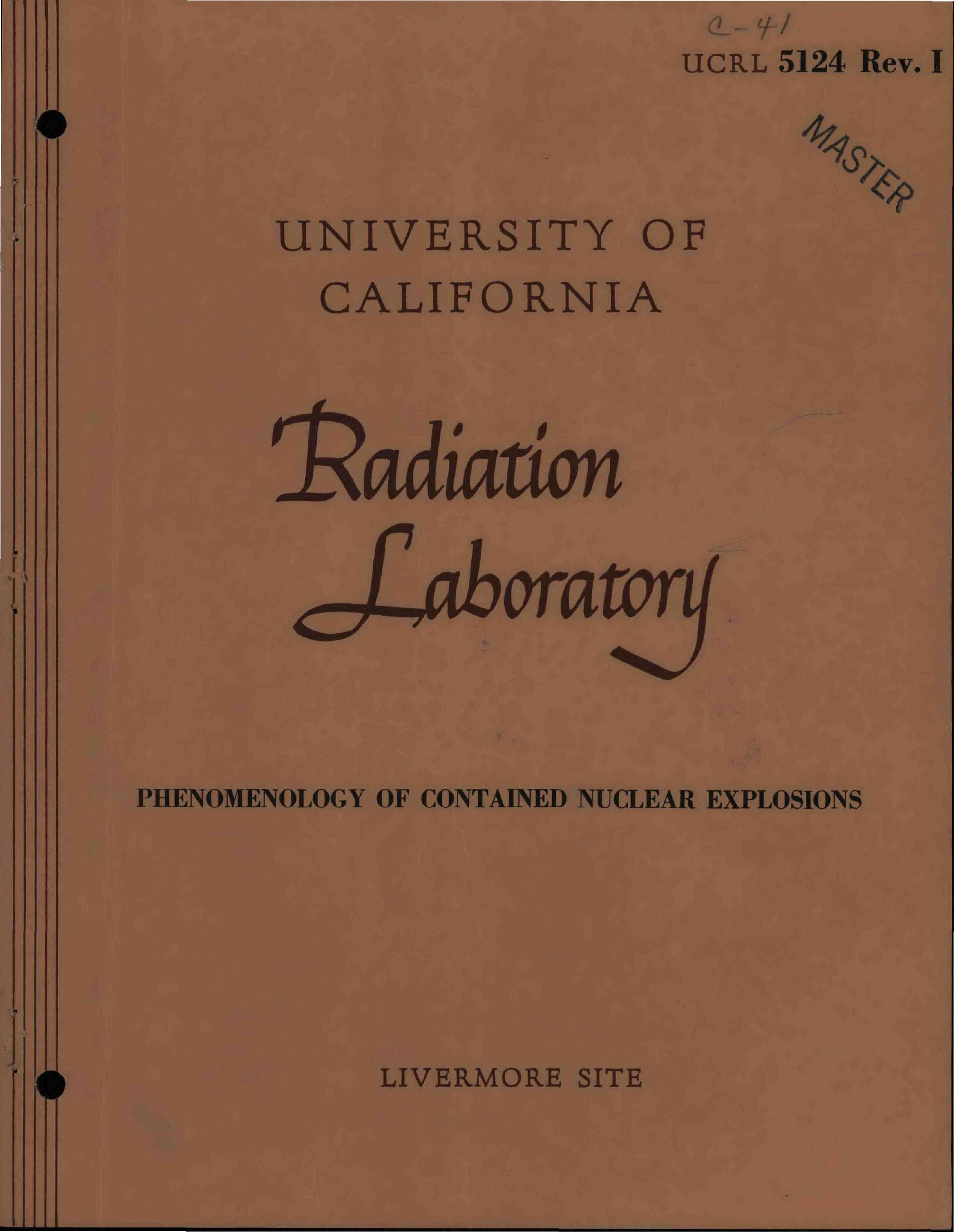

\title{
PHENOMENOLOGY OF CONTAINED NUCLEAR EXPLOSIONS
}

LIVERMORE SITE 


\section{DISCLAIMER}

This report was prepared as an account of work sponsored by an agency of the United States Government. Neither the United States Government nor any agency Thereof, nor any of their employees, makes any warranty, express or implied, or assumes any legal liability or responsibility for the accuracy, completeness, or usefulness of any information, apparatus, product, or process disclosed, or represents that its use would not infringe privately owned rights. Reference herein to any specific commercial product, process, or service by trade name, trademark, manufacturer, or otherwise does not necessarily constitute or imply its endorsement, recommendation, or favoring by the United States Government or any agency thereof. The views and opinions of authors expressed herein do not necessarily state or reflect those of the United States Government or any agency thereof. 


\section{DISCLAIMER}

Portions of this document may be illegible in electronic image products. Images are produced from the best available original document. 
UCRL-5124 Rev.I

UNIVERSITY OF CALIFORNIA

Lawrence Radiation Laboratory

Livermore, California

Contract No. W-7405-eng-48

PHENOMENOLOGY OF CONTAINED NUCLEAR EXPLOSIONS

Gerald W. Johnson and Charles E. Violet

December 1958

Printed for the U.S. Atomic Energy Commission 


\section{PHENOMENOLOGY OF CONTAINED NUCLEAR EXPLOSIONS ${ }^{*}$}

Gerald W. Johnson and Charles E. Violet

University of California

Lawrence Radiation Laboratory, Livermore, California

December 1958

\section{INTRODUCTION}

On September 19, 1957, the first completely contained nuclear explosion was fired at the Nevada Test Site. The results of this explosion as well as its significance have been discussed in considerable detail. $1,2,3,4$ The explosion had an energy release equivalent to 1700 tons of high explosive. Since one ton is defined as $10^{9}$ calories the total energy release was $1.7 \times 10^{12}$ calories. During the month of October, 1958, several additional underground shots were detonated at various scaled depths with energy releases from about 100 tons to more than 20 kilotons. In this paper the phenomenology of the first explosion, code name "Rainier", will be discussed, as it is now understood. In addition, the gross results of the more recent explosions will be given.

\section{THE RAINIER EVENT}

The Rainier detonation took place in a room $6 \mathrm{ft} \times 6 \mathrm{ft} \times 7 \mathrm{ft}$ at the end of a tunnel driven into the side of a mountain. The vertical depth of burial was $899 \mathrm{ft}$ and the distance to the nearest point on the sloping face of the mountain was $790 \mathrm{ft}$. The scaled depth is given by $\mathrm{D} / \mathrm{w}^{1 / 3}=\frac{790}{(1.7)^{1 / 3}}=$ $663 \mathrm{ft}$. D is the actual depth in feet and W the energy release in kilotons. The geology of the mountain as determined by the USGS ${ }^{5}$ is characterized by a cap of welded tuff about $250 \mathrm{ft}$ thick which is underlain by several layers of bedded tuffs to a depth of about 2,000 ft. The basement

\footnotetext{
* This report is based on a joint paper given at the Fourth Annual Symposium on Mining Research held at Rolla, Missouri, Nov. 13, 1958. The work was performed under the auspices of the U.S. Atomic Energy Commission.
} 
rock is dolomite. The tuffs vary from unconsolidated to consolidated. The tunnel itself was in a consolidated bed so that no shoring was required. The tunnel section was about $7 \mathrm{ft} \times 8 \mathrm{ft}$. The geological structure and the location of the shot point with respect to the surface is shown in Fig. 1.

The average properties of the medium surrounding the point of detonation are listed in the following sections: The physical properties listed are intended to represent our best estimates of the average properties of the medium within $100 \mathrm{ft}$ of the center of detonation. The samples were all collected in the vicinity of the point of detonation prior to the shot. The magnitudes often represent averages of measurements made by various groups. 6

Density:

Bulk density in situ

$1.9-2.0 \mathrm{~g} / \mathrm{cm}^{3}$

Bulk density dry

$1.70 \pm 0.1 \mathrm{~g} / \mathrm{cm}^{3}$

Water content by weight

$15 \%-35 \%$

Porosity

$25 \%-35 \%$

Grain density

$2.29 \pm 0.05 \mathrm{~g} / \mathrm{cm}^{3}$

Most of the water contained in the rock is released by heating to $110^{\circ} \mathrm{C}$. At this temperature $80 \%$ of the water is released, by heating to $600^{\circ} \mathrm{C}$ another $18 \%$ is released, and about $2 \%$ more by heating to $1000^{\circ} \mathrm{C}$.

Bulk Modulus:

The measurement was made at $25^{\circ} \mathrm{C}$ and in the pressure range 0 5000 psi. The modulus as measured for jacketed samples was the same for both dry and saturated tuff and is $3.5 \times 10^{10}$ dynes $/ \mathrm{cm}^{2}$.

Specific Heat:

The specific heat for the dry rock in the range of $25^{\circ} \mathrm{C}$ to $600^{\circ} \mathrm{C}$ and for wet rock in the range $25^{\circ} \mathrm{C}$ to $100^{\circ} \mathrm{C}$ was calculated from the chemical composition.

\section{Dry Rock}

Temperature $\quad 25^{\circ} \mathrm{C} \quad 100^{\circ} \mathrm{C} \quad 200^{\circ} \mathrm{C} \quad 400^{\circ} \mathrm{C} \quad 600^{\circ} \mathrm{C}$

$\begin{array}{llllll}\text { Specific heat: } & 0.180 & 0.211 & 0.236 & 0.272 & 0.300\end{array}$


DESCR IPTION OF BEDDINGS

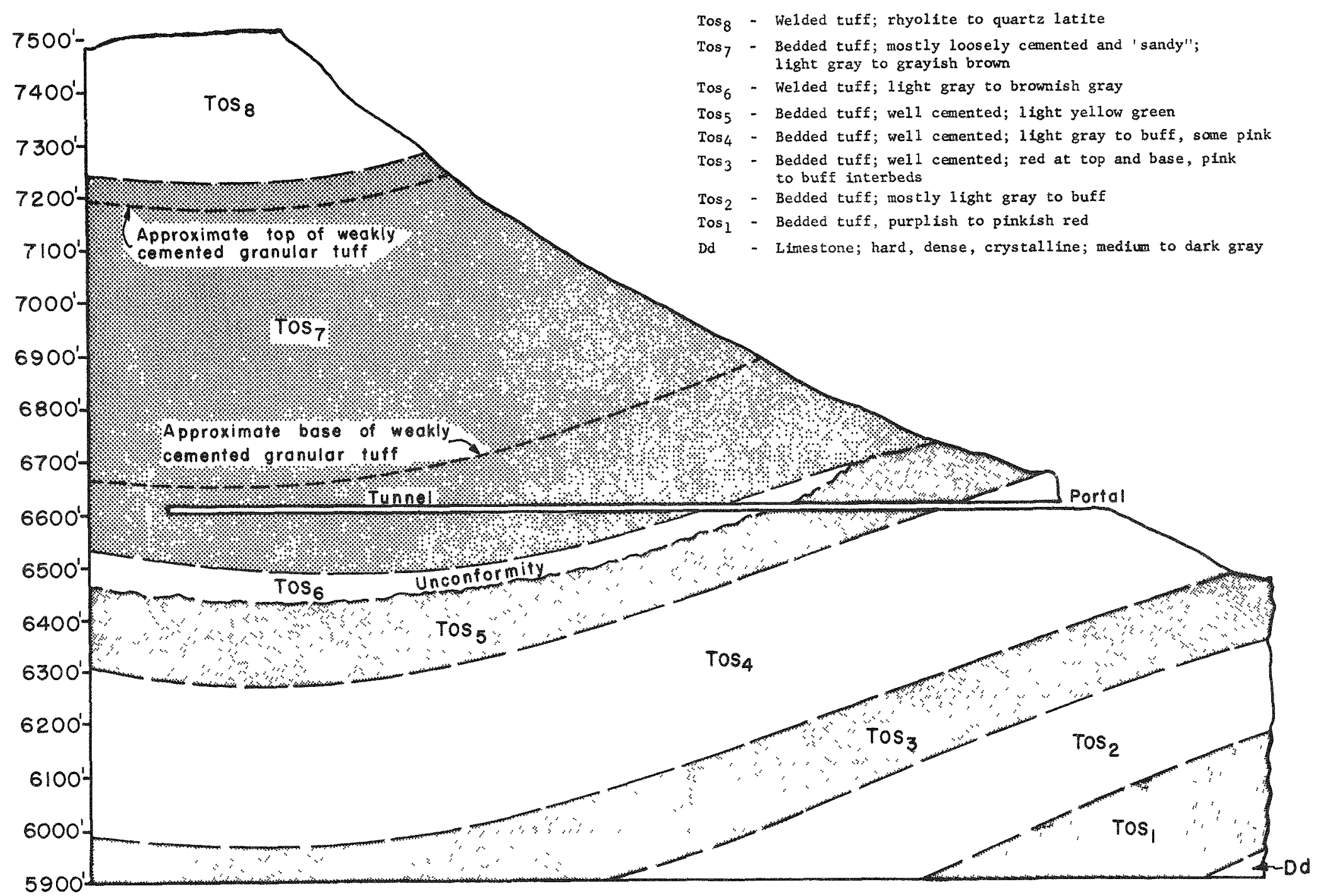

MuL-4162 Fig. 1. Profile of tunnel site with geologic characteristics, Rainier Event. 


\section{Saturated Rock}

Temperature: $\quad 25^{\circ} \mathrm{C} \quad 100^{\circ} \mathrm{C}$

Specific heat: $\quad 0.30 \quad 0.32$

$\left(\mathrm{cal} / \mathrm{g} /{ }^{\circ} \mathrm{C}\right.$ )

Specific heat for saturated rock does not include heat of vaporization.

Chemical Analysis (Fraction by dry weight):

$\begin{array}{rl}\mathrm{SiO}_{2}-76 \% & \mathrm{~K}_{2} \mathrm{O}-5.0 \% \\ \mathrm{Al}_{2} \mathrm{O}_{3}-13 \% & \mathrm{MgO}-0.5 \% \\ \mathrm{Fe}_{2} \mathrm{O}_{3}-1.5 \% & \mathrm{CaO}-1 \% \\ \mathrm{FeO}-0.05 \% & \mathrm{CO}_{2}-0.2 \% \\ \mathrm{Na}_{2} \mathrm{O}-2.0 \% & \end{array}$

Compressive Strength:

$3.5-7.0 \times 10^{8}$ dynes $/ \mathrm{cm}^{2}$

Thermal Conductivity (at $\left.29.0^{\circ} \pm 0.3^{\circ} \mathrm{C}\right)$ :

Dehydrated

Saturated

$$
\begin{aligned}
& \mathrm{K}=1.70 \times 10^{-3} \mathrm{cal} / \mathrm{cm} \mathrm{sec}{ }^{\circ} \mathrm{C} \\
& \mathrm{K}=2.60 \times 10^{-3} \mathrm{cal} / \mathrm{cm} \mathrm{sec}^{\circ} \mathrm{C}
\end{aligned}
$$

Sound Velocity (measured in situ):

$\approx 2.4 \times 10^{5} \mathrm{~cm} / \mathrm{sec}$

Petrography:

There is a marked similarity in all tuff samples taken from this region of the Nevada Test Site. The predominant constituant is a matrix of fine-grained zeolites including heulandite, cristobalite and montmorillonite. Less than $10 \%$ by volume is represented as phenocrysts, mainly alkaline feldspar.

Fusion Tests:

Cones prepared from crushed samples were heated in a furnace. All deformed in the range $1280-1300^{\circ} \mathrm{C}$. On account of the large glass content no great volume change would be expected on fusing.

The tunnel was terminated in a spiral (Fig. 2) designed by G.T. Pelsor ${ }^{7}$ and B. Sussholz ${ }^{8}$ of such dimensions that it was expected to seal itself by collapse before any radioactive debris could project around the spiral and out the tunnel. Prior to the detonation, the re was considerable concern 


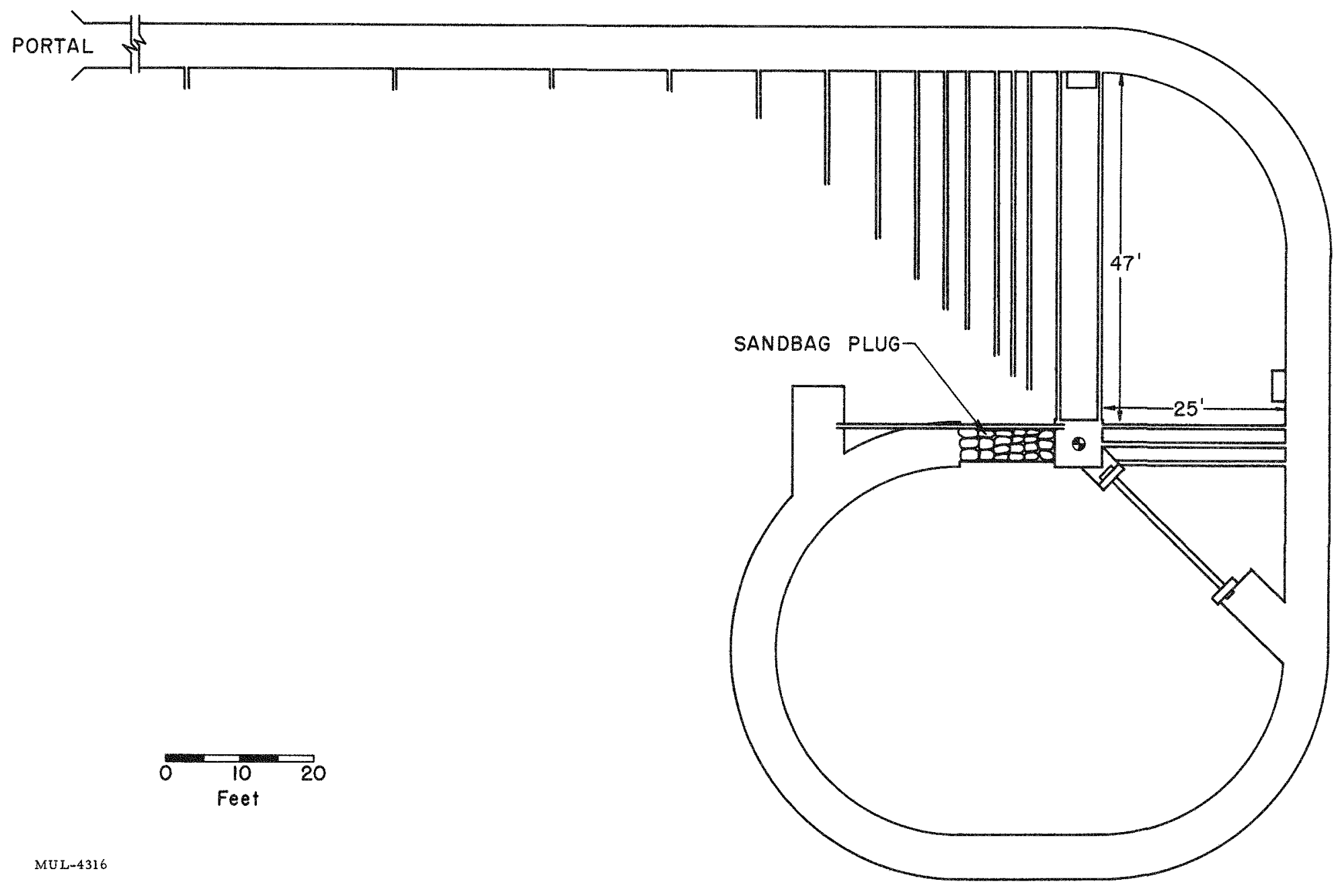

Fig. 2. Preshot tunnel configuration in region of detonation. 
that radial fracturing either to the tunnel or the surface might prevent containment of the radioactive products by this simple design.

\section{RESULTS FROM THE RAINIER EVENT}

The Rainier device was detonated at $09 \mathrm{hr} 59 \mathrm{~min} 59.45 \mathrm{sec}$, Pacific daylight time, on September 19, 1957. The coordinates of the center of detonation were Lat. $N 37^{\circ} 11^{\prime} 44.80^{\prime \prime}$, Long. W $116^{\circ} 12^{\prime} 11.35^{\prime \prime}$, and the elevation was $6611 \mathrm{ft}$.

From the firing point at 2.5 miles few people felt any ground shock. Some heard a muffled boom. Scattered rocks were shaken loose from the cap rock of the hill for distances of about $1 / 2$ mile each side of the point of detonation.

Inspection of the tunnel after the shot revealed that collapse of the tunnel had occurred at a radial distance of $200 \mathrm{ft}$ and that spalling had continued to about $400 \mathrm{ft}$. Beyond that distance to the portal, except for occasional spalling there was no damage. The total amount of spalled material beyond $400 \mathrm{ft}$ amounted to a few cubic yards. At $1100 \mathrm{ft}$ from the center of detonation there was a shift along a bedding plane of about 0.35 ft.

As far as could be determined, the radioactivity was completely contained, although small leaks to the surface could have evaded detection. None was discovered inside the tunnel in excess of natural background $(0.04 \mathrm{mr} / \mathrm{hr})$ as measured prior to the explosion. A search using the most sensitive radiochemical techniques was made for radioactive is otopes of the rare gases, krypton and xenon. The concentrations of these gases were below the limits of detectability, namely $1 \times 10^{10}$ fission $/ \mathrm{ft}^{3}$. It is believed that no leak of activity occurred to the surface; however, small leaks might not have been detected due to high background ( 20 milliroentgens/hr) from previous air bursts.

Acceleration and displacement measurements by the Stanford $R \mathbf{R}-$ search Institute, Edgerton, Germeshausen and Grier, Inc., and Sandia Corporation $9,10,11$ indicated that directly above the point of detonation the shock arrived at $146 \mathrm{~ms}$ and the maximum vertical excursion was 9 in. The vertical displacement at horizontal radii of $1000 \mathrm{ft}$ from a point 
on surface directly above the detonation was less than $1 / 2$ in. Analysis of all results indicated that a block about 100 - $200 \mathrm{ft}$ thick separated and rose and fell as a unit. The maximum acceleration on the surface was $5.8 \mathrm{~g}$ at $186 \mathrm{~ms}$ and the maximum displacement of $9 \mathrm{in}$. occurred at $350 \mathrm{~ms}$.

Rainier seismic effects were measured by U.S. Coast and Geodetic Survey ${ }^{12}$ and the U.S. Geological Survey. ${ }^{5}$ Seismic signals were detected at various stations in the continental U.S. and at distances up to 1000 miles. Seismic signals were also detected (though barely resolved) at College Station in Fairbanks, Alaska at a distance of 2200 miles.

\section{PHENOMENOLOGY OF THE RAINIER EVENT}

From an analysis of cores obtained from drill holes into the Rainier zero site as well as measurements made in these holes, the sequence of events immediately following the explosion can be reconstructed. The initial conditions in the zero room can be calculated as follows:

Energy density: $E=E_{p}+E_{r}=3 / 2 n k T+\frac{4 \sigma T^{4}}{c}$

where

$$
\begin{aligned}
& E_{p}=\text { energy density in the particles } \\
& E_{x}=\text { energy density in radiation } \\
& \mathrm{n}=\frac{\mathrm{A}_{\mathrm{o}} \mathrm{P}}{\mathrm{M}}=\text { number of particles per } \mathrm{cm}^{3} \\
& k=1.37 \times 10^{-16} \mathrm{erg} /{ }^{\circ} \mathrm{K} \text { (Boltzmann's constant) } \\
& \mathrm{T}=\text { Temperature }{ }^{\circ} \mathrm{K} \\
& \sigma=5.74 \times 10^{-5} \mathrm{erg} / \mathrm{cm}^{2} /{ }^{\circ} \mathrm{K}^{4} \text { (Stephan-Boltzmann } \\
& \text { constant) } \\
& c=3 \times 10^{10} \mathrm{~cm} / \mathrm{sec} \text { (velocity of light) } \\
& A_{o}=6.03 \times 10^{23} \text { (Avogadro's number) } \\
& M=\text { molecular weight } \\
& \rho=\text { density in } \mathrm{g} / \mathrm{cm}^{3}
\end{aligned}
$$

This can be put in the form

$$
\begin{aligned}
E & =3 / 2 \frac{A_{o} \rho}{M} k T+\frac{4 \sigma T^{4}}{c} \\
& =1.25 \times 10^{8} \frac{\rho}{M} T+7.65 \times 10^{-15} T^{4} \mathrm{erg} / \mathrm{cm}^{3}
\end{aligned}
$$

The pressure equals $2 / 3$ particle energy density plus $1 / 3$ radiation energy density, thus

$$
P=0.83 \times 10^{8} \frac{\rho}{M} \mathrm{~T}+2.55 \times 10^{-15} \mathrm{~T}^{4} \text { dynes } / \mathrm{cm}^{2}
$$


Knowledge of the energy release, volume and mass of material in the zero room enables the calculation of initial temperature and pressure. The energy release of the explosion was $7.2 \times 10^{19}$ ergs (one kiloton releases $10^{12} \times 4.2 \times 10^{7}=4.2 \times 10^{19} \mathrm{ergs}$ ). Since the mass of material in the room was about $10^{6} \mathrm{~g}(1 \mathrm{ton})$ and the volume was $7 \times 10^{6} \mathrm{~cm}^{3}$, the mean density was $0.14 \mathrm{~g} / \mathrm{cm}^{3}$. At these extremely high temperatures essentially all electrons are stripped from nuclei and since the atomic weight is approximately twice the atomic number, the effective molecular weight is given by:

$$
M_{\text {eff }} \approx \frac{\Sigma N_{i} \times 2 Z_{i}}{\sum N_{i}\left(Z_{i}+1\right)} \approx 2
$$

where $N_{i}=$ number of atoms of atomic number $Z_{i}$.

The summation is taken over all atoms in the zero room. Therefore, one can calculate that at the time the energy was distributed in the room the temperature was about $1,000,000^{\circ} \mathrm{K}$ and the pressure 7,000,000 atmospheres (bars). The radiation pressure at this temperature is 2500 bars which is negligible compared with the particle pressure.

The shock for about the first three feet was sufficiently strong to vaporize the rock, and to melt it out to $15 \mathrm{ft}$. The rock was crushed out to a radius of about $130 \mathrm{ft}$. From the time of arrival measurements and the equation of state of the medium, the pressure vs distance can be calculated 7,13 and is given in Fig. 3.

As the shock moved outward, the room expanded spherically and reached a radius of $55 \mathrm{ft}$ in several milliseconds. At this time the cavity was lined with about $4 \mathrm{in}$. of melted rock (that which was initially contained in a sphere of radius $15 \mathrm{ft}$ about the center of detonation) at a temperature of $1200-1500^{\circ} \mathrm{C}$. The description of the state of the cavity at these times and the mechanisms of its collapse are given in detail by Kennedy and Higgins. ${ }^{2}$ The cavity when first formed was filled with steam at a pressure of 40 atmospheres which is approximately the lithostatic pressure. The cavity stood long enough, between $30 \mathrm{sec}$ and 2 min, for much of the fluid rock to flow down the sides and to drip from the roof. At this time the cavity began to collapse and the cavity cooled rapidly due to expansion of the steam quenching some of the droplets of rock in free fall, as well as some of the "icicles" as they hung suspended 


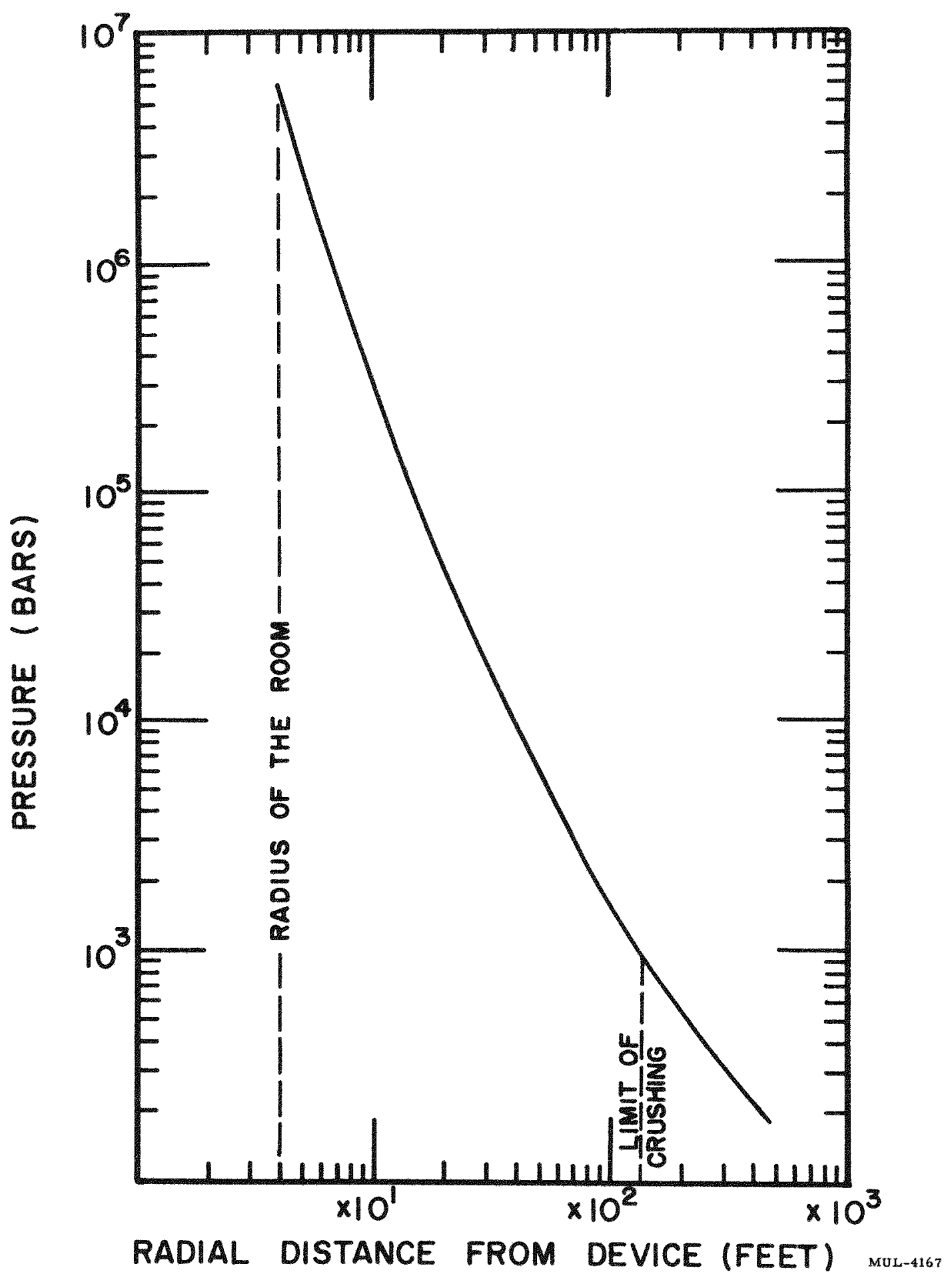

Fig. 3. Shock pressure vs radial distance for Rainier Event. 
from the cavity roof. See Fig. 4. The cavity was filled with broken rock from the collapse, and the caving progressed successively vertically to a distance of $386 \mathrm{ft}$ above the point of detonation. Because of the presence of water and the large permeable region produced by the collapsed cavity, the melted rock rapidly cooled to the temperature of boiling water $93^{\circ} \mathrm{C}$ $(6600 \mathrm{ft}$ altitude). All of the rock which was initially melted converted to a glass on cooling. The glass was found to contain all of the radioactive fission products except the rare gases. The sequence of events in the collapse of the cavity is illustrated in Fig. 5.

The model described here is based on data from one drill hole from the surface vertically downward through the region of the detonation and from three cored holes from within the tunnel." Drilling vertically revealed no radioactivity until the drill broke through into a 25 -ft-high cavity at a depth of $516 \mathrm{ft}$ (Fig. 5). The dimensions of the cavity were not measured but photographs taken inside the cavity indicated roughly a cone with a height of $25 \mathrm{ft}$. From this point down to the center of detonation, the rock was broken and permeable as indicated by the failure to recover cores and the loss of drilling water. Here for the first time, a radioactive isotope of krypton $\left(\mathrm{Kr}^{85}\right)$ was detected $\left(5-9 \times 10^{14}\right.$ fissions $\left./ \mathrm{ft}^{3}\right)$. The activity on the solid material was $\sim 10^{9}$ fissions/cu ft. Both these levels are many orders of magnitude below acceptable tolerance levels. Drilling radially from the tunnel at different elevations revealed a crushed impermeable zone from a radius of $130 \mathrm{ft}$ to $55 \mathrm{ft}$ and a permeable region within the $55-\mathrm{ft}$ radius. Figure 6 shows the orientation of the underground drill holes.

Logging the drilled holes for temperature and radioactivity 14,15 gave the results shown in Fig. 7 and 8 . From the facts that the radioactivity seems to be concentrated in a bowl-shaped shell of radius of about $55 \mathrm{ft}$, that the temperature tends to equalize within that radius, and that drilling water was lost within that radius, it was concluded that the initial cavity radius was $55 \mathrm{ft}$.

Radiochemical analysis 16 of the glass and the surrounding medium showed that almost all the activity was trapped in this highly insoluble

* The advice and assistance of L.E. Shaffer, University of California, Berkeley, in the postshot drilling program is gratefully acknowledged. 


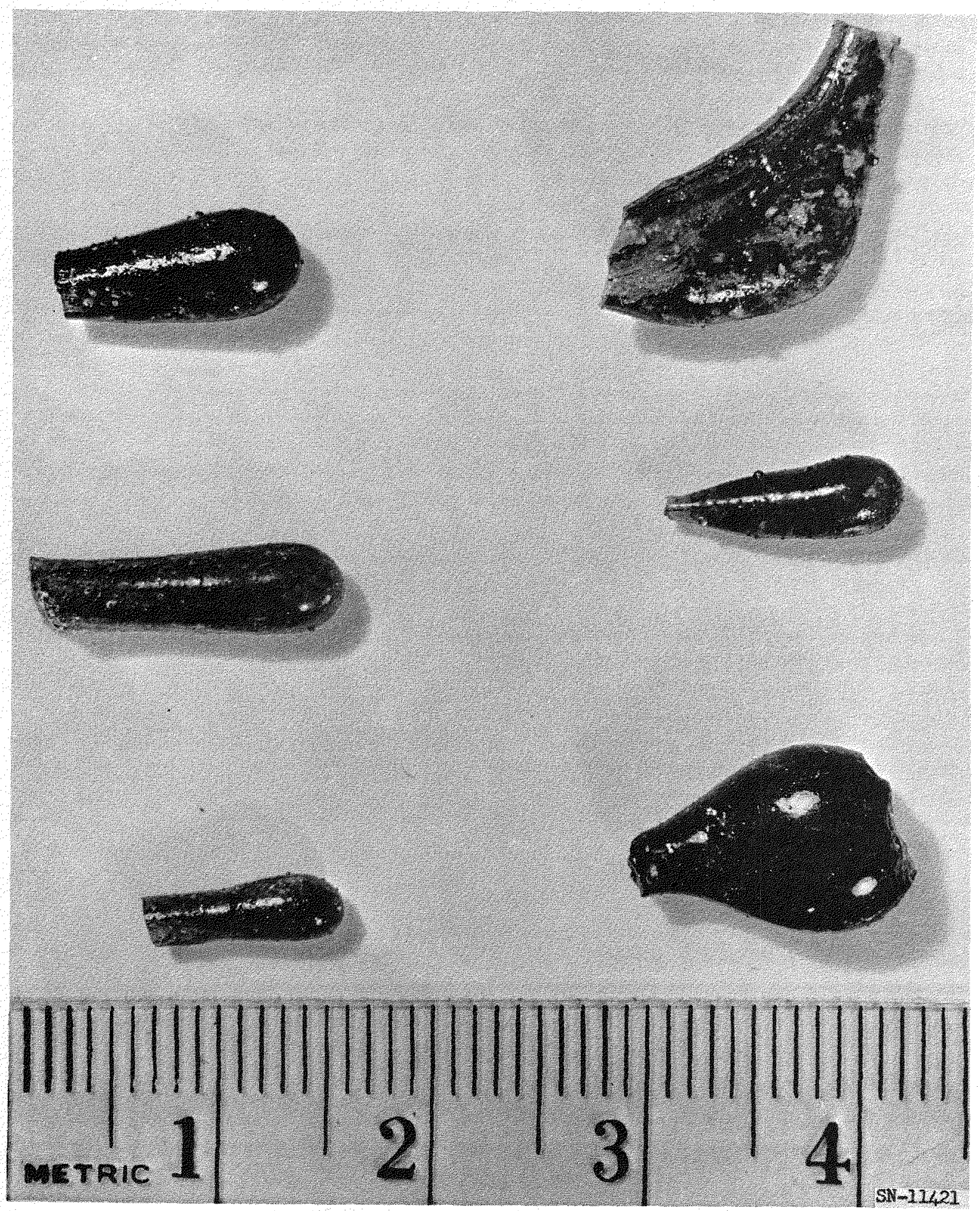

Fig. 4. Droplets and icicles of fuzed tuff from Rainier cavity. 


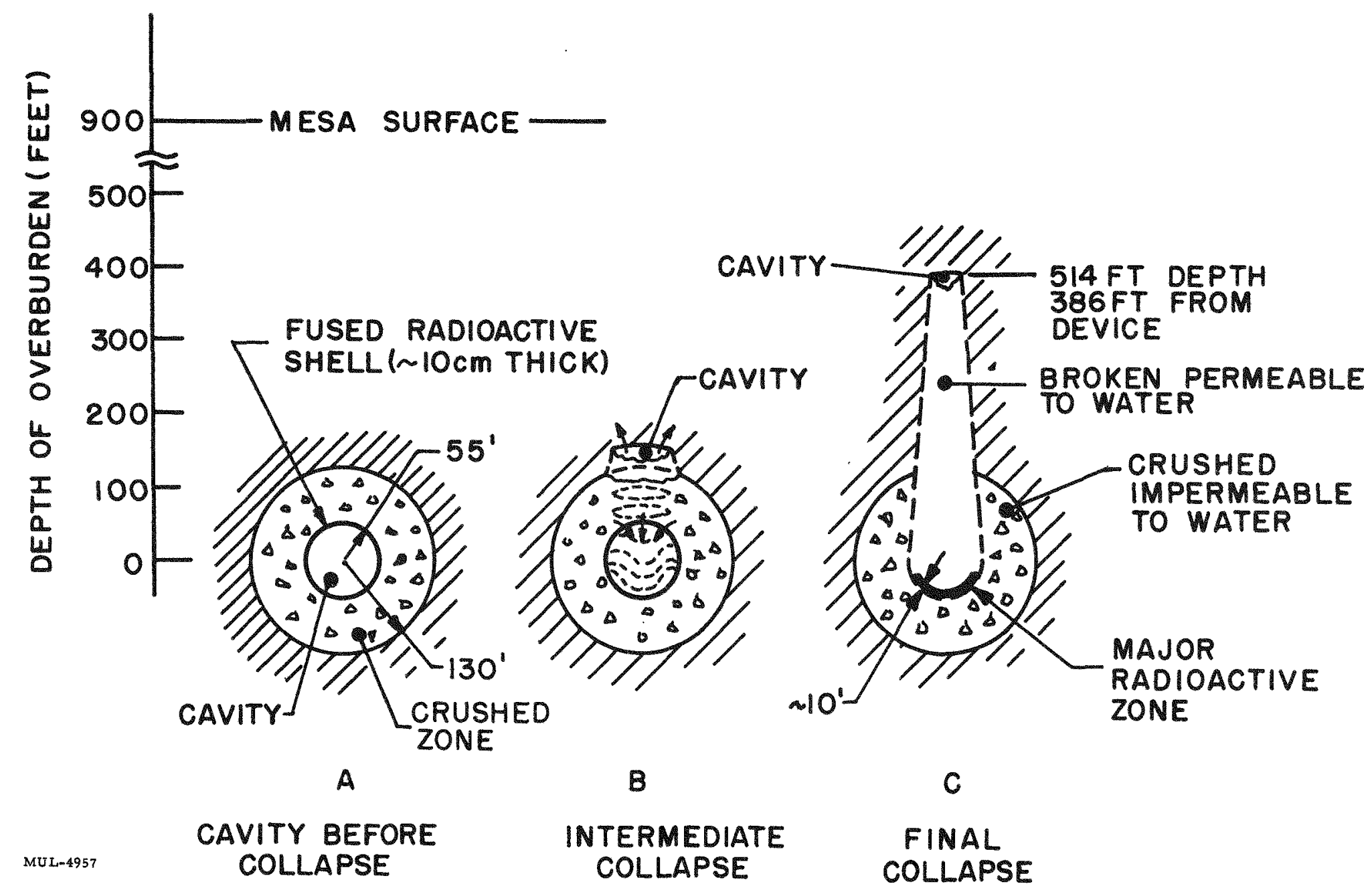

Fig. 5. Reconstructed picture of strongly affected zones surrounding detonation point, Rainier Event. 

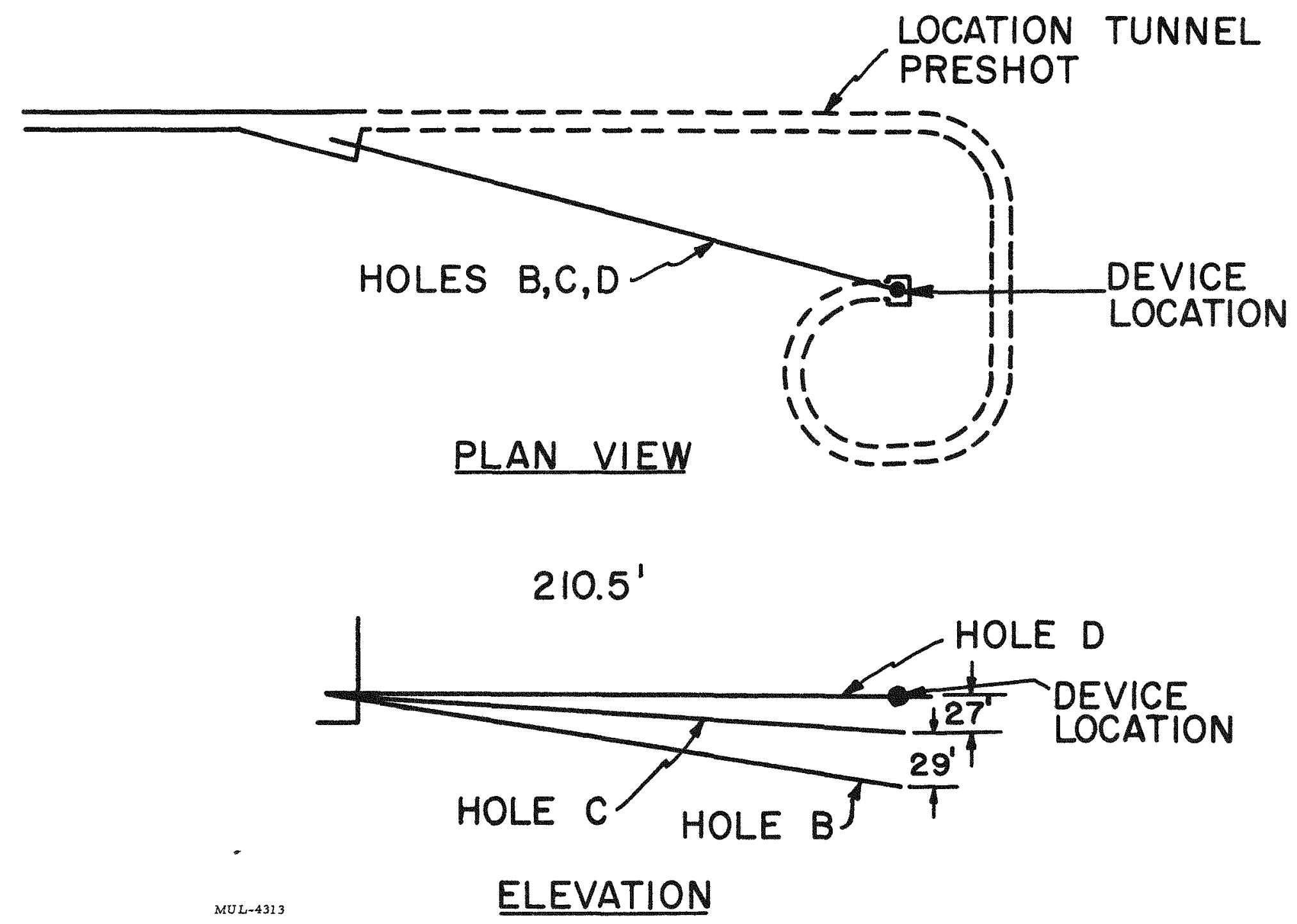

Fig. 6. Locations of postshot drill holes. 


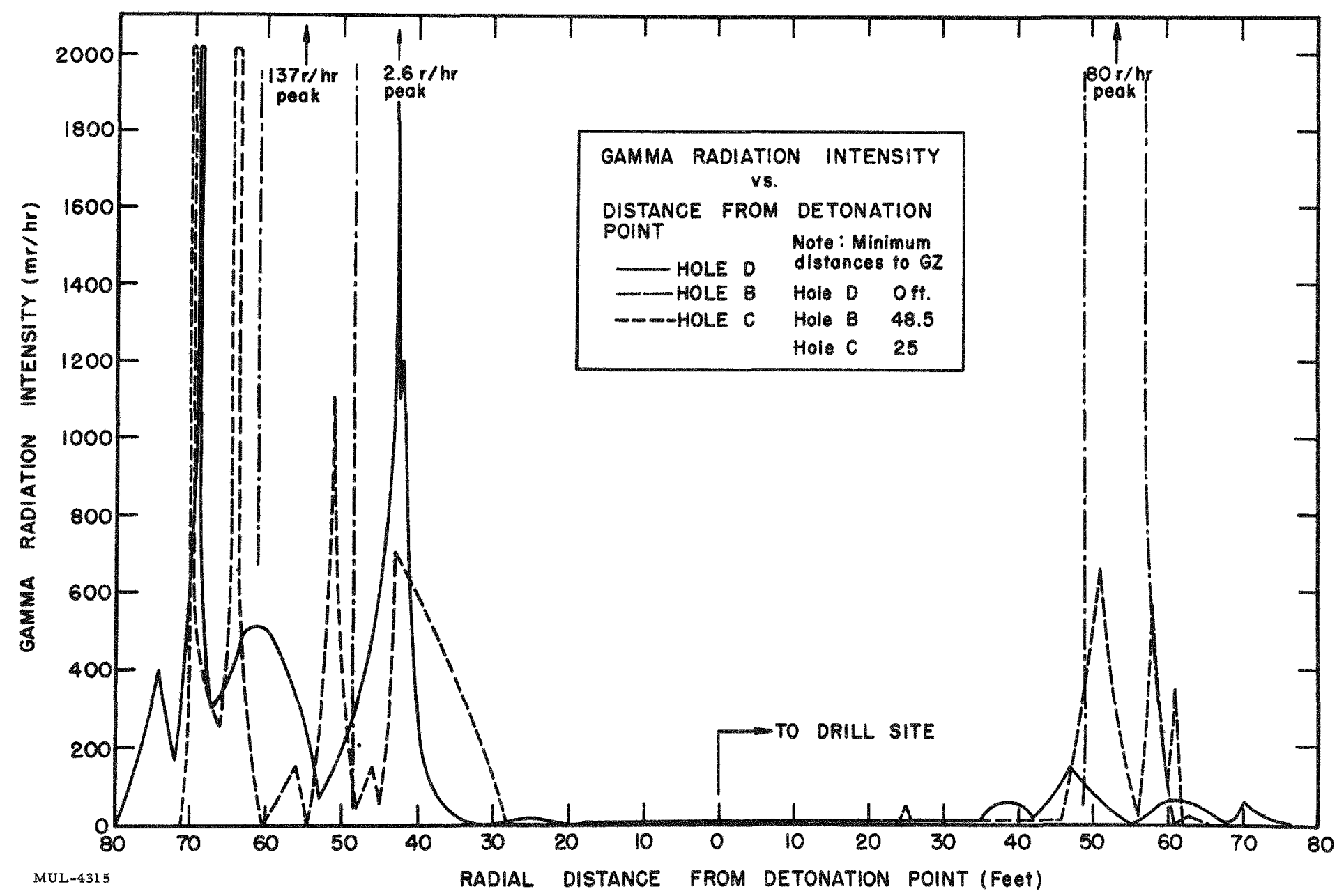

$\frac{1}{1}$

Fig. 7. Postshot radiation logs of holes $B, C$ and $D$. Date of logging $-F e b .11-13$, $1958(D+146$ days). 


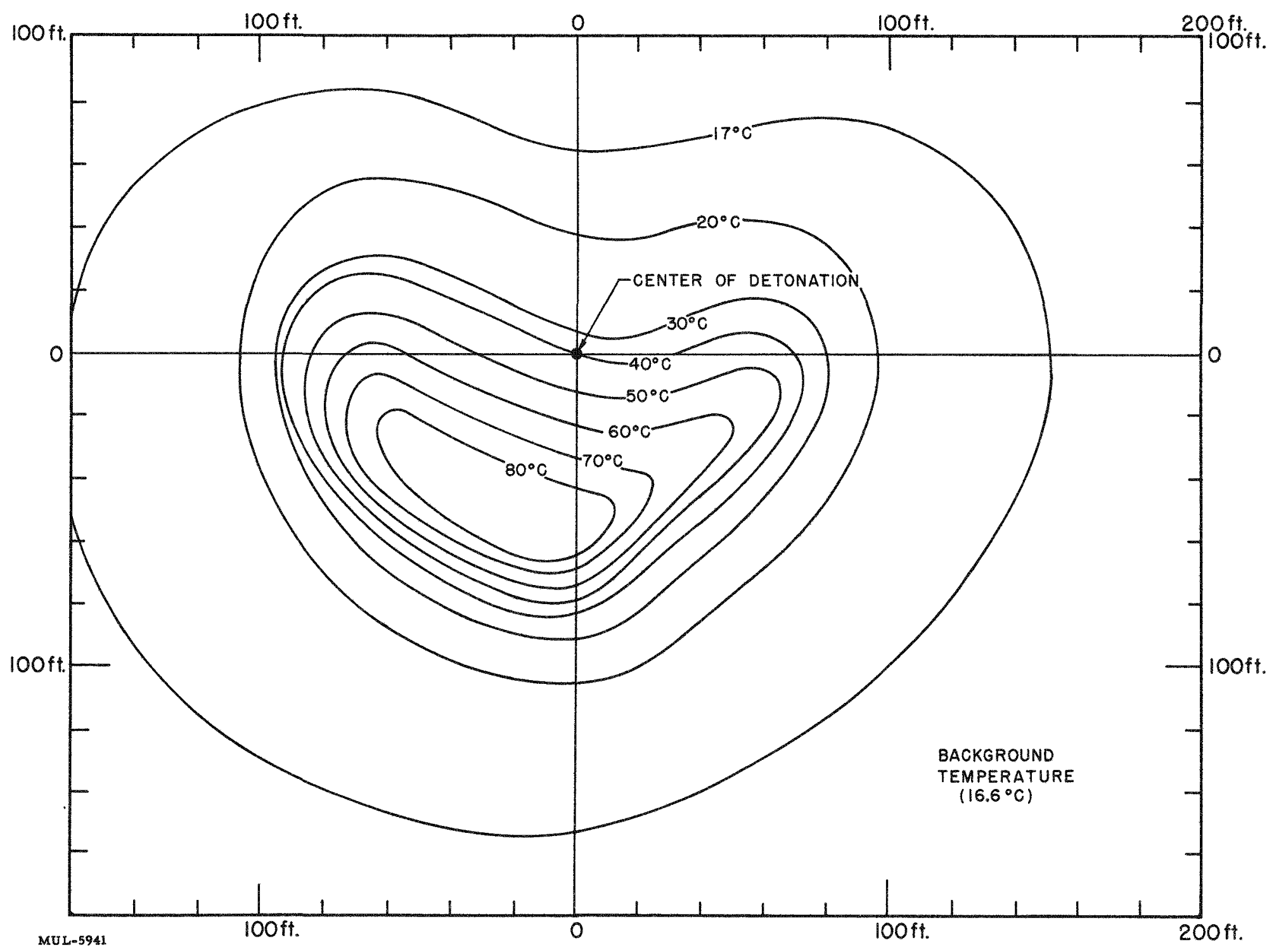

Fig. 8. Temperature in vertical plane surrounding the Rainier detonation point, measured five months after detonation. 
material and also that 700 tons was melted. From this number, one calculates that a 4 -in. shell on a 55-ft radius was melted. It is also known that rock will melt at a shock strength of $10^{5}$ bars and above. A calculation, using Fig. 2, of the amount of material within the $10^{5}$ bar contour ( $15 \mathrm{ft}$ ) gives a value of 760 tons which is in good agreement with the more reliable radiochemical number.

From the temperature of the melted rock $\left(1500^{\circ} \mathrm{C}\right)$, the pressure due to steam in the cavity can be calculated to be 40 bars, which can be compared with the lithostatic pressure 50-55 bars. An experimental confirmation of this estimate was made by Kennedy and Higgins ${ }^{2}$ by heating some of the glass, which had condensed in free fall, in a vacuum furnace to drive out the gas. From the measured quantity of trapped gas, it was calculated that the pressure in the contained bubbles was 40 bars. The agreement between the computed pressure based on the estimated amount of rock fused and its water content with the pressure based on measurements of the amount of water in the quenched glass droplets is remarkable.

To heat 700 tons of the tuff $(20 \%$ water $)$ to $1200-1500^{\circ} \mathrm{C}$ would require $5 \times 10^{11}$ calories, which is one-third of the total energy release of the explosion. The shock, while not strong enough to melt the rock beyond the 55-ft radius, was still strong enough to do work on and hence heat the medium. The temperature rose above background at a radius of $130 \mathrm{ft}$. Integration of the energy content of the heated rock, using the contours of Fig. 8, shows that about one half of the total energy released remains locally in the form of heat.

A study by George Morey ${ }^{17}$ of the action of heat and superheated steam on Oak Springs tuff revealed that in air it will flow under its own weight at $1200^{\circ} \mathrm{C}$, but even at higher temperatures it is extremely viscous. A detailed description of the petrographic changes in the mineral as a function of temperature up to $1200^{\circ} \mathrm{C}$ is contained in his report. An important possible diagnostic effect was reported, namely that the mineral heulandite $\left(\mathrm{Ca}_{3} \mathrm{Na}_{2}\right) \mathrm{O} \cdot \mathrm{Al}_{2} \mathrm{O}_{3} \cdot 6 \mathrm{SiO}_{2} \cdot 5 \mathrm{H}_{2} \mathrm{O}$ which makes up about $70 \%$ of the material, undergoes a phase change at $290^{\circ} \mathrm{C}$ which can be clearly resolved using $x$-ray diffraction techniques. The new phase has not yet been identified, however, it may turn out that this effect can be used advantageously in studying tuff external to the melted region to determine 
the radius at which the material was heated to $290^{\circ} \mathrm{C}$. This may contribute materially to the understanding of the early phenomenology.

Leaching tests on a number of samples obtained from the fused shell region were conducted at Oak Ridge National Laboratory. ${ }^{18}$ specimens were crushed and sieved to divide the particles into a number of size classifications. One-gram samples of the crushed material were subjected to leaching tests at room temperature with $100 \mathrm{ml}$ of ground water from a drill hole near the Rainier site. Since these tests were run using the smallest size particles ( $<53$ microns), under stirred conditions, and with a 100-to-l weight ratio of water to specimen it is believed that this should represent the least favorable conditions for retention of activity in the residue. The results show that less than 0.55 percent of the activity was leached over a 48-hour period. This small amount of activity leached under the most stringent conditions is strong evidence that the availability of fission product activity to the ground water system is extremely small.

\section{CONCLUSIONS FROM RAINIER}

The radioactivity, with negligible exceptions, was all trapped in the 700 tons of melted rock. When the cavity collapsed this material fell to the bottom of the cavity. Experiments with this material has shown that it is in fine solution in the glass and is unavailable in amounts sufficient to cause ground water contamination.

The region produced by collapse of the cavity, comprising some 200,000 tons, is highly permeable to water and is not contaminated by radioactive debris.

The crushed region produced by the shock is much less permeable; in this material the return of water used for exploratory drilling was complete. In addition, gaseous radioactive fission products did not penetrate into this region during or after the explosion.

More than one half the total energy release of the bomb $(1700$ tons = $1.7 \times 10^{12}$ calories) was contained in rock initially at high temperature (above $200^{\circ} \mathrm{C}$ ). Because of the presence of large quantities of water and the high permeability of the central region, the heat redistributed itself to the temperature of boiling water. 
The seismic ground shock was not felt beyond a distance of 2.5 miles. Electrical cabling and electronics recording systems housed in a light metalframe building at a distance of 2,000 ft from the center of detonation suffered no damage or visually observed effects of any sort.

\section{UNDERGROUND NUCLEAR DETONATIONS OF OCTOBER, 1958}

\section{A. LOGAN}

Logan was detonated at $2200 \mathrm{hr} 0.14 \pm 0.01 \mathrm{sec}$, Pacific standard time, on October 15, 1958. The coordinates of the shot point are Lat. $N$ $37^{\circ} 11^{\prime} 03^{\prime \prime}$ and Long.W 116 $16^{\circ} 14^{\prime} 04^{\prime \prime}$ at an altitude of $6136 \mathrm{ft}$. The total energy release has not yet been measured but is estimated at $4.5 \pm 1 \mathrm{kt}$. The device was placed at the end of a straight tunnel in a room of dimensions $31 \mathrm{ft}$ long $\times 9 \mathrm{ft}$ high $\times 9 \mathrm{ft}$ wide. The vertical depth of burial was $930 \mathrm{ft}$ and the nearest point to the surface $830 \mathrm{ft}$ (Fig. 9). The scaled depth was $500 \mathrm{ft}$.

The radioactive debris produced by the explosion was completely contained. There was no measured radioactivity either on the surface or into the tunnel. The main tunnel collapsed at a radial distance of $820 \mathrm{ft}$. In a side drift for a future shot the floor displaced upward and there was a large amount of debris broken from the overhead at radial distance of $700 \mathrm{ft}$. There was a thrust of $2.5 \mathrm{ft}$ at a bedding plane at a radial distance of $1,500 \mathrm{ft}$. The blower system and instrument shelters in the portal area at a distance of 2,700 ft were undamaged.

The ground shock was readily felt by observers at a distance of 2.5 miles but not at 7 miles.

\section{B. TAMALPAIS}

Tamalpais was fired on October 8,1958 , at $1400 \mathrm{hr} 0.14 \pm 0.01 \mathrm{sec}_{8}$ Pacific standard time. The location of the point of detonation was Lat. $N$ $37^{\circ} 11^{\prime} 43.10^{\prime \prime}$, Long.W $116^{\circ} 12^{\prime} 01.65^{\prime \prime}$ and elevation $6616 \mathrm{ft}$. The total measured energy release was $65 \pm 20$ tons. The device was placed in a room of dimensions $20 \mathrm{ft} \times 20 \mathrm{ft} \times 17 \mathrm{ft} \mathrm{high,} \mathrm{which} \mathrm{was} \mathrm{lined} \mathrm{on} \mathrm{all} \mathrm{sides}$ by two feet of salt. The salt was introduced to give preliminary data of interest in the planned Plowshare experiment in a deep salt bed near Carlsbad, 


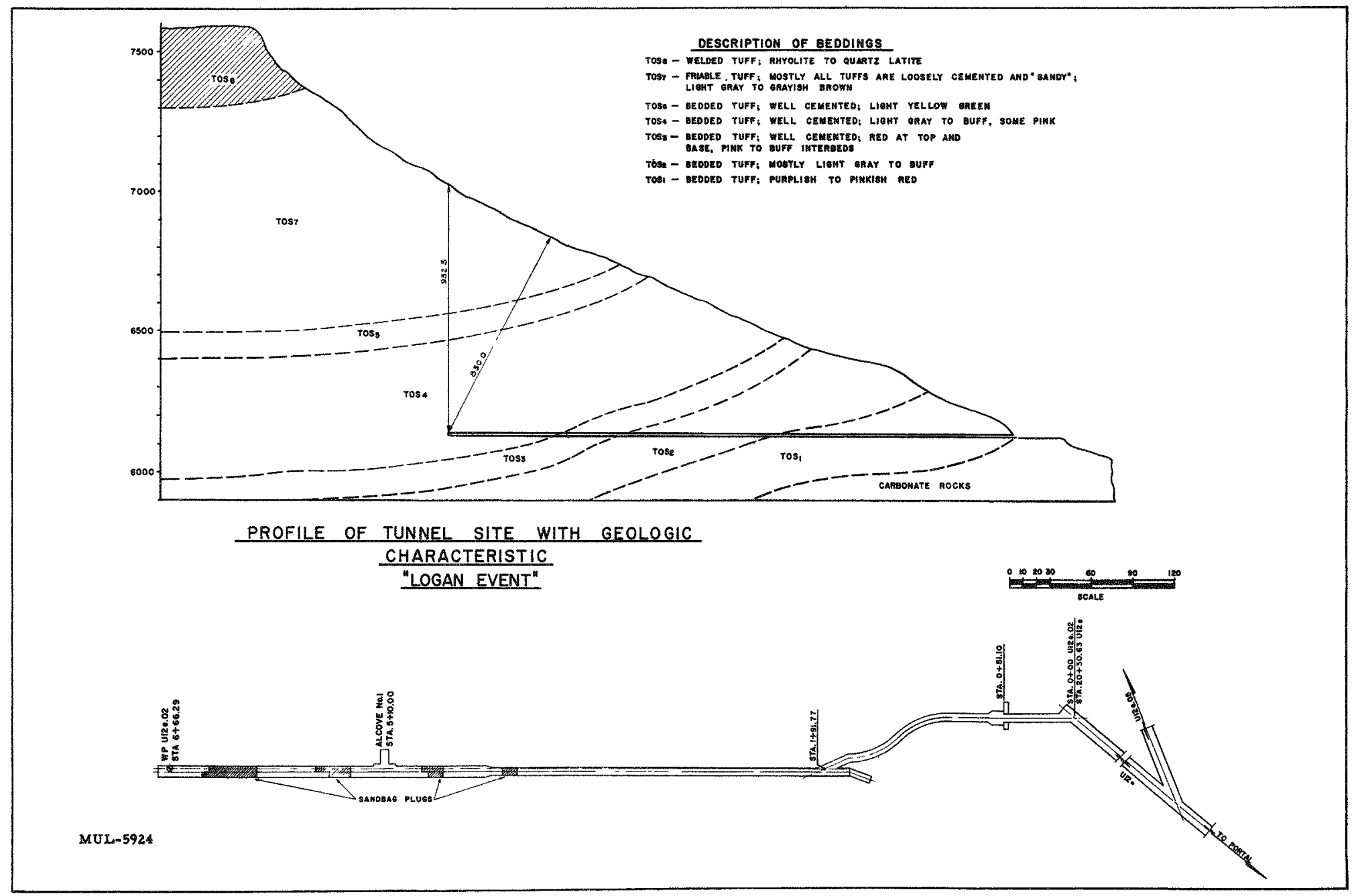

Fig. 9. Profile of tunnel site with geologic characteristic, Logan Event. 
New Mexico, to be conducted during the fall of 1959. The vertical depth was $410 \mathrm{ft}$ and the nearest point to the surface was $330 \mathrm{ft}$. The scaled depth was $825 \mathrm{ft}$ (Fig. 10). The geological formation surrounding the shot chamber is a bedded tuff and is located in the same general stratum as was the Rainier explosion.

Following the detonation, the tunnel collapsed and sealed most of the radioactive products. However, gaseous fission products (isotopes of Xe and $\mathrm{Kr}$ ) along with water vapor, hydrogen and organic gases, such as $\mathrm{CO}, \mathrm{C}_{2} \mathrm{H}_{6}$ and $\mathrm{C}_{2} \mathrm{H}_{2}$, escaped from the zero room into the tunnel. These gases were pumped from the tunnel without leaving radioactive residues of any significance. However, the explosive gases were in such concentrations and amounts as to create a hazardous situation. Chemical analysis ${ }^{20}$ of these gases shows that about $10^{6}$ moles of $\mathrm{H}_{2}$ were produced. The zero room contained large amounts of organic material such as wood, cable insulation and paraffin. It is interesting to note that all of the hydrogen could not have been produced from the paraffin. More than half must have come from other sources, probably water.

The blast door designed to support a static load of $75 \mathrm{psi}$, but not gas-tight, remained in place intact at a radial distance of $144 \mathrm{ft}$. An instrument alcove which was supported with steel sets was undamaged at a radial distance of $140 \mathrm{ft}$. There was no damage to any of the tunnels beyond this point. The nearest point to the main drift, which had no shoring, was $237 \mathrm{ft}$, and although the shock contacted the tunnel at normal incidence there occurred no damage at this point.

The seismic signal was not felt by individuals at the firing point (2.5 miles).

\section{NEPTUNE}

Neptune was fired on October 14, 1958, at $1000 \mathrm{hr} \pm 1 \mathrm{sec}$, Pacific standard time. The location of the shot point was Lat. N $37^{\circ} 11^{\prime} 37.885^{\prime \prime}$, Long. W 116 $11^{\prime} 58.886^{\prime \prime}$ and at an elevation of $6712 \mathrm{ft}$. The total measured energy release was $100 \pm 10$ tons. The shot room had dimensions of $12 \mathrm{ft} \times 17 \mathrm{ft} \times 10 \mathrm{ft}$ high. The vertical depth was $109.5 \mathrm{ft}$ and the nearest point to the surface was $98.5 \mathrm{ft}$. The scaled depth was $210 \mathrm{ft}$ (Fig. 11).

On detonation a large amount of material was heaved out of the sloping side of the mountain. There was some venting of radioactive material ( 1 to $2 \%$ ) at the time of cratex formation. The dimensions of the crater are approximately $200 \mathrm{ft}$ transverse to the mesa contour line and $150 \mathrm{ft}$ 


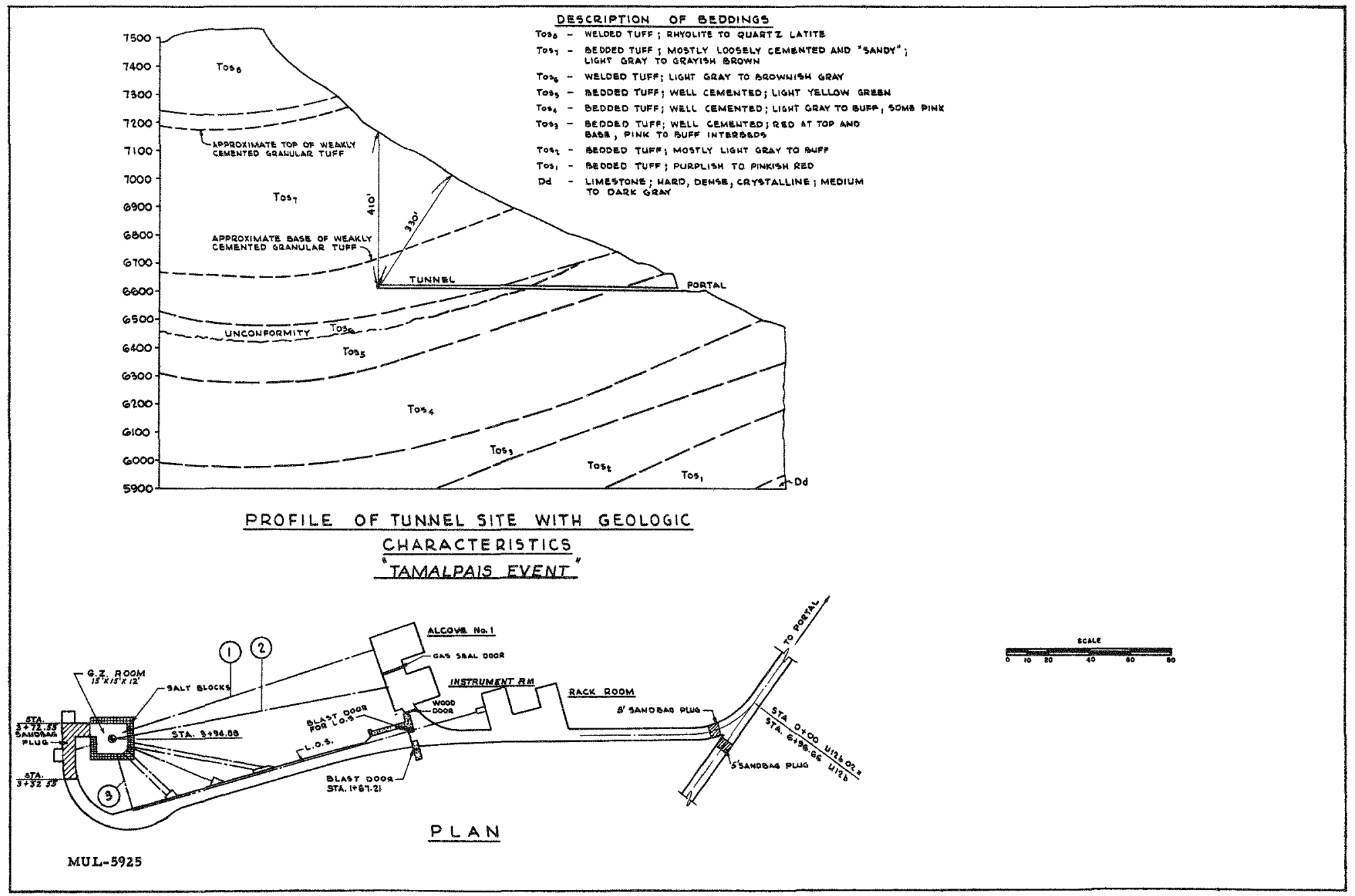

Fig. 10. Profile of tunnel site with geologic characteristic, Tamalpais Event. 


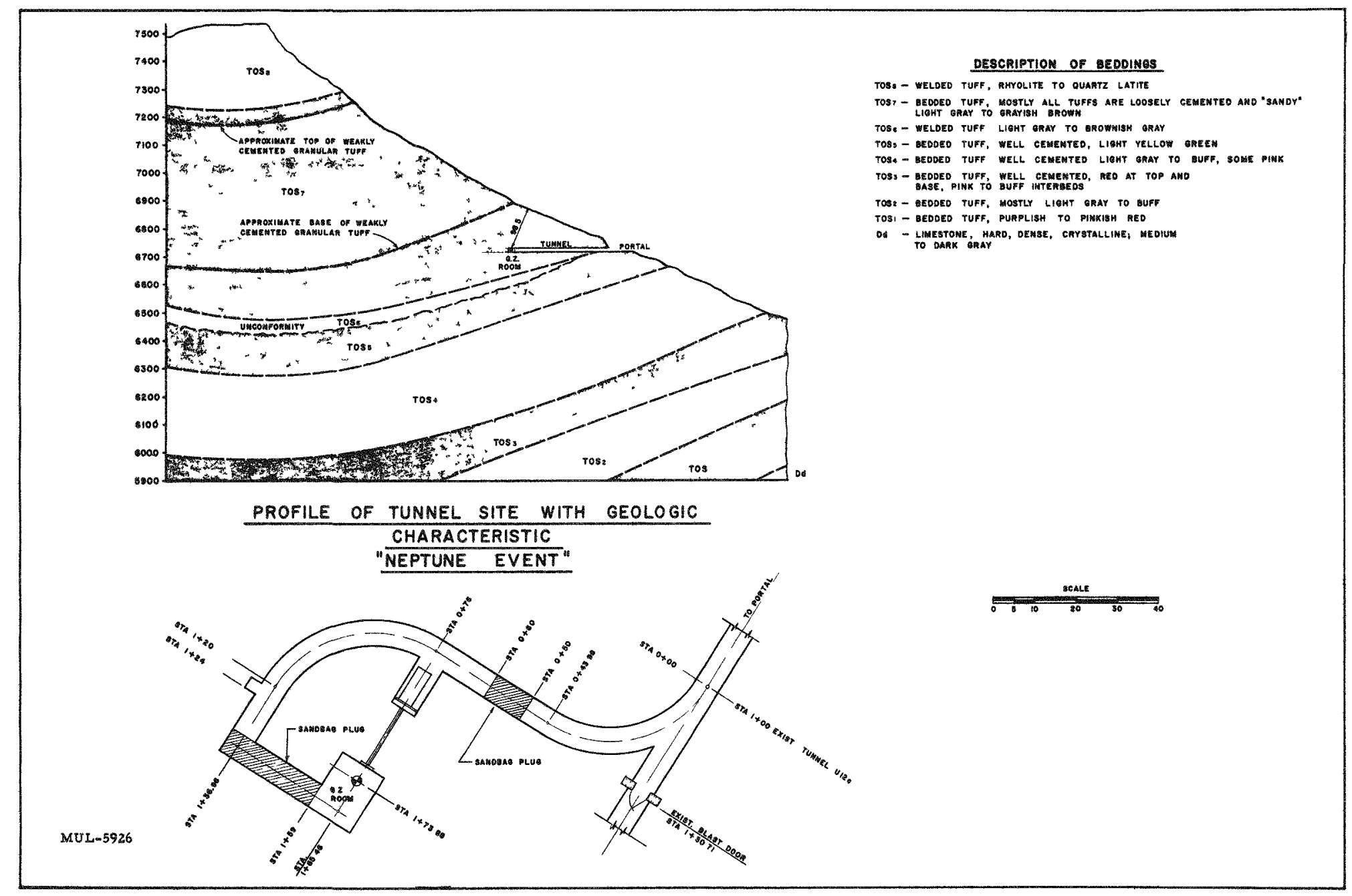

Fig. 11. Profile of tunnel site with geologic characteristic, Neptune Event. 
along the contour line by $40 \mathrm{ft}$ deep. It is estimated that $33,000 \mathrm{cu}$ yds of material were displaced down the slope.

There was very little radioactive contamination of the surface exposure of the broken rock produced by the explosion. Except for a small spot about $40 \mathrm{ft} \times 80 \mathrm{ft}$ where a jet came out and where the level was up to $1 \mathrm{r} /$ hour, the measured levels in and near the crater 5 days after the explosion were down to less than $100 \mathrm{mr} /$ hour. The explosion took place at a radial distance of $156 \mathrm{ft}$ from another tunnel (Rainier) which, except for a small amount of spallation, suffered no damage.

\section{BLANCA}

Blanca was fired on October 30,1958 at $0700 \mathrm{hr} 00.15 \pm 0.1 \mathrm{sec}$, Pacific standard time. The location of the shot point was Lat. $\mathrm{N} 37^{\circ} 11^{\prime}$ 09. 368', Long. W $116^{\circ} 12^{\prime} 07.280^{\prime \prime}$ and at an elevation of $6138 \mathrm{ft}$. The measured energy release was $23 \pm 3$ kilotons. The shot room was $7 \mathrm{ft} x$ $8 \mathrm{ft} \times 20 \mathrm{ft}$. The vertical depth was $988 \mathrm{ft}$ and the nearest point to the surface was $835 \mathrm{ft}$. Scaled depth was $290 \mathrm{ft}$ (Fig. 12).

On detonation the shock was clearly visible in its effect of kicking up soil as it broke through the sloping of the mountain. A large quantity of the cap rock was broken loose and fell down the sides of the mountain. About 15 seconds after zero time a plume of dust was ejected from the mountain due to the collapse of the initial cavity to the surface. The dust rose about $1000 \mathrm{ft}$ and carried some radioactivity with it. The fraction of radioactivity which escaped is estimated ${ }^{19}$ to have been $0.1 \%$. There was a very small but detectable leak of radioactivity into the tunnel. The damage to the tunnel was mostly a repeat of that which was done by Logan. The major collapse was at a radial distance of about $850 \mathrm{ft}$. There was a thrust of about $3 \mathrm{ft}$ along a bedding plane at a distance of $1500 \mathrm{ft}$ and movement of about $1 \mathrm{ft}$ vertically on a fault at a distance of $2200 \mathrm{ft}$. There was no damage to blower installations or instrument stations at the portal at a distance of $2700 \mathrm{ft}$.

The ground shock was felt strongly by observers at a distance of 5 miles and was noticeable as a rolling effect at 16 miles, but not at 20 miles. At a distance of 2 miles the earth motion was strong enough to rock automobiles violently from side to side. 


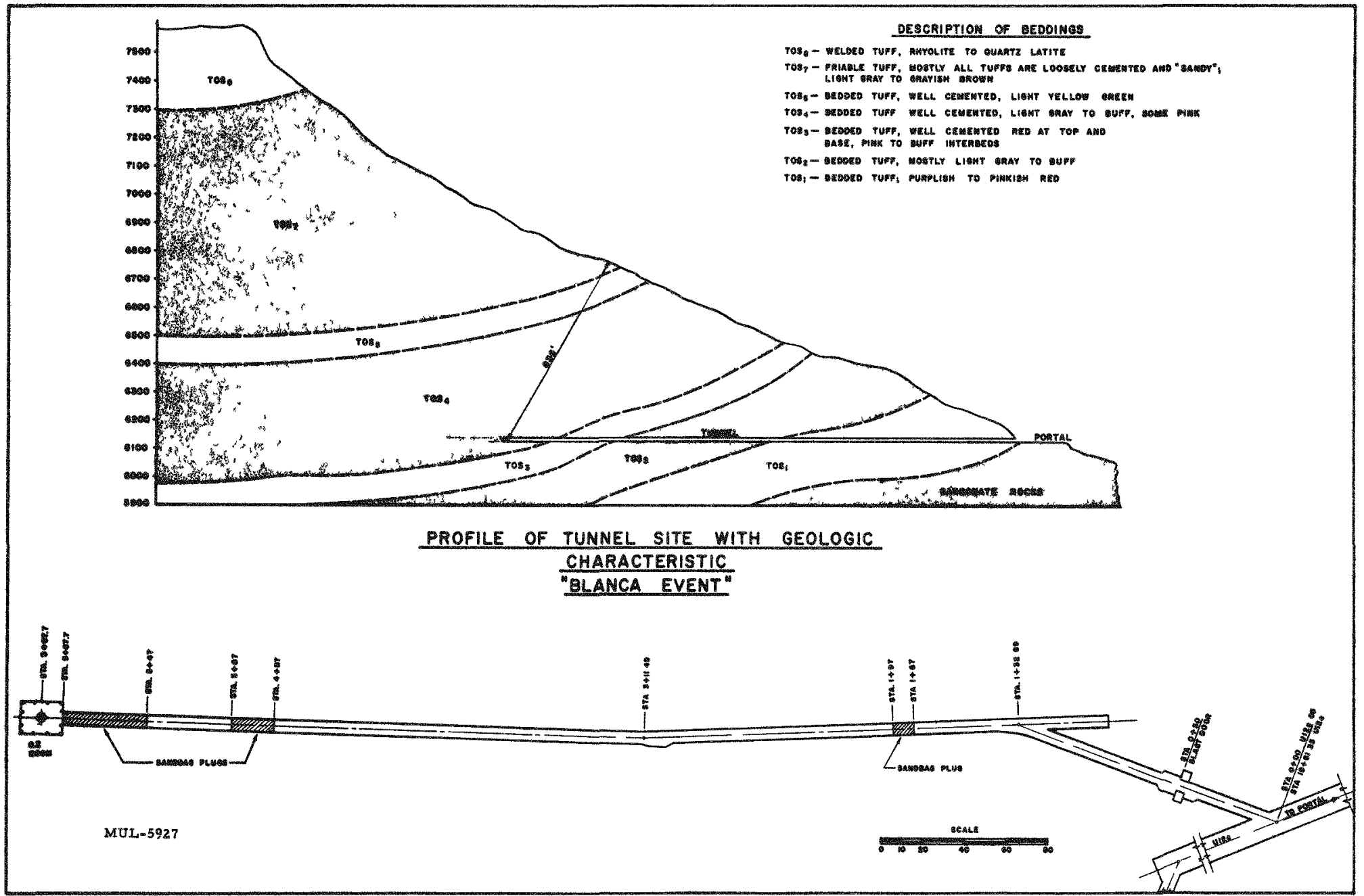

Fig. 12. Profile of tunnel site with geologic characteristic, Blanca Event. 
Detailed reports on each of these explosions will be prepared and published by University of California Lawrence Radiation Laboratory and other participating agencies.

\section{CONCLUSIONS}

At this point it is clear that for explosions in the kiloton region and above that complete containment of all radioactive debris can be expected for scaled depths of $450 \mathrm{w}^{1 / 3} \mathrm{ft}$ although at $290 \mathrm{w}^{1 / 3} \mathrm{ft}$ only $0.1 \%$ escaped. For shallower depths some escape may be expected up to 1 to $2 \%$ for scaled depths of $210 \mathrm{~W}^{1 / 3} \mathrm{ft}$. Close-in structural damage appears to be limited to distances of about $1000 \mathrm{~W}^{1 / 3} \mathrm{ft}$, though this distance will depend on location of local planes of weakness in the geological structure.

\section{REFERENCES}

1. G.W. Johnson, G.T. Pelsor, R.G. Preston, and C.E. Violet, "The Underground Nuclear Detonation of Sept. 19, 1957 - Rainier, Operation Plumbbob," UCRL-5124, Feb. 4, 1958.

2. G.C. Kennedy and G.H. Higgins, "Temperatures and Pressures Associated with the Cavity Produced by the Rainier Event, "UCRL-5281, July 1958.

3. H. Brown and G.W. Johnson, "Non-Military Uses of Nuclear Explosions," UCRL-5026, June 12, 1958.

4. G.W. Johnson, "Rainier Blast Opens New Horizons," Engineering and Mining Journal, April 1958.

5. Unpublished data, courtesy of U.S. Geological Survey.

6. W.H. Diment, G.V. Keller, E.C.Robertson, R.E. Wilcox, and T. Botinelly, U.S. Geological Survey, private communication.

7. G.T. Pelsor, University of California, Lawrence Radiation Laboratory, Livermore, California, private communication.

8. B. Sussholz, Space Technology Laboratories, Inc., Los Angeles 45, California.

9. L.M. Swift, D.C. Sachs, J.L. Brenner, and W.M. Wells, "Surface Motion from an Underground Detonation, "Stanford Research Institute, ITR-1528, Oct. 15, 1957. 


\section{REFERENCES (Contd.)}

10. Staff of Edgerton, Germeshausen and Grier, Inc., "Photographic Analysis of Earth Motion, Shot Rainier,"WT-1532, May 1958.

11. W.R. Perret and R.G. Preston, "Preliminary Summary Report of Strong-Motion Measurements from a Confined Underground Nuclear Detonation, "Sandia Corporation and University of California Radiation Laboratory, ITR-1499, June 15, 1958.

12. D.S. Carder, W.K. Cloud, L.M. Murphy, and J.H. Hershberger, "Surface Motions from an Underground Explosion," U.S. Coast and Geodetic Survey, WT-1530 (to be published).

13. S. Cohn, A. Hoehn, R.G. Dickens, F.B. Porzel, T. Schiffman, S. Hoenig, N. Wilde, and C. Greenberg, "Close-In Time-of-Arrival Measurements for Yield of U6 Shot," Armour Research Foundation, WT-1495, (to be published).

14. D.E. Nielsen, University of California, Lawrence Radiation Laboratory, private communication.

15. B. Ragent, Broadview Research Corp., Burlingame, California, private communication.

16. R.H. Goeckerman, University of California, Lawrence Radiation Laboratory, private communication.

17. G.W. Morey, U.S. Geological Survey, private communication.

18. F.R. Bruce, W.D. Bond, and W.E. Clark, Oak Ridge National Laboratory, private communication.

19. A. Vay Shelton, Jr., University of California, Lawrence Radiation Laboratory, private communication.

20. G. H. Higgins, University of California, Lawrence Radiation Laboratory, private communication.

Note: ITR and WT numbered reports may be obtained by writing to: AEC Technical Information Service Extension, P. O. Box 401, Oak Ridge, Tenn., or, Office of Technical Services, Department of Commerce, Washington $25, \mathrm{D} . \mathrm{C}$.

$/ \mathrm{jm}$ 
This report was prepared as an account of Government sponsored work. Neither the United States, nor the Commission, nor any person acting on behalf of the Commission:

A. Makes any warranty or representation, express or implied, with respect to the accuracy, completeness, or usefulness of the information contained in this report, or that the use of any information, apparatus, method, or process disclosed in this report may not infringe privately owned rights; or

B. Assumes any liabilities with respect to the use of, or for damages resulting from the use of any information, apparatus, method, or process disclosed in this report.

As used in the above, "person acting on behalf of the Commission" includes any employee or contractor of the Commission to the extent that such employee or contractor prepares, handles or distributes, or provides access to, any information pursuant to his employment or contract with the Commission.

Price \$1.00. Available from the Office of Technical Services, Department of Commerce, Washington $25, \mathrm{D}$. C. 